\title{
Prisão e políticas públicas: Uma análise do encarceramento feminino no estado do Ceará
}

\section{Prision and public policies: A women incarceration investigation in the Ceará State}

\author{
Ana Gabriela Mendes Braga* \\ Paula Pereira Gonçalves Alves*
}

\section{Resumo}

O escopo do presente artigo é analisar o modelo de políticas públicas destinadas às mulheres em situação de prisão, a partir da experiência do estado do Ceará. Para tanto, utilizou-se da abordagem empírica, com emprego do método de estudo de caso e das técnicas de entrevista e visita in loco. Num primeiro momento, buscou-se descrever as significações de políticas públicas e algumas de suas espécies, tais como política penitenciária e criminal. Parte-se da hipótese de que a concretização de políticas públicas é um caminho para a efetividade da dignidade de mulheres em situação de prisão. Nesse sentido, problematiza-se a existência de uma inversão ideológica que faz da prisão uma forma de política social, de modo a expandir o Estado Penal e minimizar o Estado Social. Uma alternativa para tal paradoxo diz respeito à construção de redes entre instituições da Administração Pública entre si e a sociedade civil, de modo a viabilizar melhores condições às mulheres encarceradas e respeito à dignidade dessas pessoas. Desde essa perspectiva, a experiência do estado do Ceará adquire fundamental importância para o atual cenário brasileiro em matéria de prisão de mulheres.

Professora da Universidade Estadual Paulista Júlio de Mesquita Filho - Unesp. Coordenadora da Pesquisa "Dar à luz na sombra" (Projeto Pensando o Direito SAL/IPEA). Doutorado Sanduíche realizado junto ao Departamento de Antropologia da Universitat de Barcelona. Doutora e Mestre em Criminologia e Direito Penal pela Universidade de São Paulo. São Paulo - SP - Brasil. E-mail: anagabrielamb@gmail.com

* Mestranda pela Universidade Estadual Paulista Júlio de Mesquita Filho - Unesp. Bacharel em Direito pela Faculdade de Direito de Franca. Bolsista Capes. São Paulo - SP - Brasil. E-mail: paulapgalves13@hotmail.com 
Palavras-chave: Prisão. Políticas públicas. Mulheres. Maternidade. Direitos humanos.

\section{Abstract}

The scope of this paper is to examine the model of public policies for women in prison situation, from the state of Ceará experience. For this purpose, we used the empirical approach with use of case study method and interview techniques and on-site visit. At first, attempted to describe the public policies of meanings and some species, such as criminal and prison policy. It starts with the assumption that the implementation of public policies is an effective way for the dignity of women in prison situation. In this sense, the existence of an ideological inversion is discusses that makes prison a form of social policy in order to expand the penal state and minimize the welfare state. An alternative to this paradox concerns the construction of networks between institutions of public administration between them and civil society in order to enable better conditions for incarcerated women and respect for dignity. From this perspective, the experience of the state of Ceará takes fundamental importance for the current Brazilian scenario on women in prison.

Keywords: Prison. Public policy. Women. Maternity. Human rights.

\section{Introdução}

O paradoxo entre superinvestimento em segurança pública e escassez de políticas sociais é passível de análise no tocante às funções não declaradas que o sistema penal exerce. Uma hipótese elencada diz respeito ao investimento em políticas penitenciárias como um meio de garantir a contenção das desordens geradas por exclusão social, desemprego e retração da proteção social do Estado.

A precariedade em matéria de políticas públicas penitenciárias no Brasil costuma ser objeto de investigação de muitos trabalhos, principalmente no campo criminológico. Contudo, para além do diagnóstico, torna-se importante mapear práticas em matéria de articulação dessas políticas, levando em consideração a perspectiva dos direitos humanos e do respeito à dignidade das pessoas. 
Ademais, outra problemática é a particularidade das políticas públicas voltadas à questão de gênero. Nesse ínterim, busca-se apontar para uma experiência de políticas penitenciárias voltadas às mulheres em situação de prisão, em particular às recém-mães ou gestantes, por meio de um estudo das políticas públicas adotadas pelo estado do Ceará. A situação de vulnerabilidade dessas mulheres é visível, assim como outras circunstâncias de vulnerabilidade dignas de políticas sociais. Por isso, investigar práticas importantes em matéria de políticas públicas é uma forma de repensar os projetos existentes que não atendem às mulheres em situação de prisão, gestantes e recém-mães, e que não estejam em sinonímia à dignidade da pessoa humana.

A partir de um estudo de caso no Ceará, no que diz respeito às mulheres em situação de prisão, será possível buscar alternativas (em curto prazo) em matéria de políticas públicas sob o enfoque dos direitos humanos enquanto iniciativas consideradas como significantes em matéria de sistema carcerário. Outrossim, num primeiro momento, é mister traçar um quadro geral a propósito do encarceramento feminino no Brasil, a fim de adentrarmos na temática de políticas públicas às mulheres presas. Em seguida, o trabalho apresenta diferenças analíticas entre políticas públicas e políticas penitenciárias, de modo a apontar a política pública como um caminho à efetividade valorativa da dignidade dessas mulheres.

O campo do estado do Ceará compõe a pesquisa "Dar à luz na sombra: condições atuais e futuras de exercício da maternidade por mulheres em situação de prisão"1 (Projeto Pensando o Direito SAL(MJ)/ IPEA), que contempla outros cinco estados brasileiros, além da unidade prisional feminina em Buenos Aires (Argentina). O recorte no presente artigo fundamenta-se pelo destaque que o Ceará teve, em decorrência do fluxo estabelecido entre Secretaria de Justiça e Cidadania do Estado do Ceará, unidade prisional, Defensoria Pública e rede da sociedade

As autoras desse artigo compuseram a equipe de pesquisa, inclusive uma delas com a coordenação da pesquisa e equipe. É possível acessar o relatório final publicado: <http:// participacao.mj.gov.br/pensandoodireito/maternidade-no-carcere/>. 
civil, uma vez que as políticas destinadas às mulheres em situação de prisão foram construídas e efetivadas sob o enfoque dos direitos humanos.

\section{Políticas públicas no cárcere: o caminho à efetivação da dignidade das mulheres presas}

O crescimento do encarceramento feminino é um fenômeno que tem se acentuado neste começo de século. Apesar de as mulheres serem minoria no sistema prisional, entre os anos de 2000 e 2012, a população carcerária masculina cresceu $130 \%$ enquanto a feminina cresceu $246 \%$. Nos anos 2000, a população carcerária feminina brasileira era de 10.112 mulheres. Já em 2012, esse número passou para mais de 35.000 mulheres presas ${ }^{2}$. Com isso, tem-se o desafio de articular políticas públicas para toda a população carcerária, que vem crescendo em grande proporção.

Se o sistema penitenciário brasileiro é internacionalmente conhecido como violador de direitos da dignidade das pessoas presas, as mulheres são ainda mais afetadas nesse cenário. Como minoria no sistema, as demandas especificas da população feminina não são atendidas e, além das violações ao exercício de direitos de forma geral, elas têm desrespeitados seus direitos sexuais e reprodutivos, assim como não tem atendidas suas necessidades específicas ligadas a vestuário, acesso à saúde especializada, necessidades familiares e psíquicas, previstas na legislação internacional (Regras de Bangkok) e na própria Lei de Execução Penal Brasileira (Lei nº 7.210/84).

A população feminina ${ }^{3}$ é composta em sua maioria por mulheres jovens, de baixa renda, pretas ou pardas, com baixa escolaridade,

Os dados mais atualizados que temos atualmente são os do Departamento Penitenciário Nacional de 2012.

3 De acordo com dados do relatório do DEPEN - Mulheres presas dados gerais, realizado com base nos dados do INFOPEN de dezembro de 2011. 
acusadas ou condenadas pelo crime de tráfico de drogas, e muitas são mães.

Questões vinculadas à pobreza e igualdade são focos de grandes pautas na agenda de políticas públicas. Contudo, tem-se o risco de que as demandas dignas de políticas públicas tornem-se fragmentadas, haja vista a ideologia presente no capitalismo maduro, voltada cada vez mais ao fortalecimento de uma política privatista, sob uma ótica de segmentação dos sujeitos sociais e redução do papel do Estado. Esse é um ponto de reflexão acerca do distanciamento sobre o ideal de um Estado do Bem-Estar Social.

A compreensão de políticas públicas enquanto legitimidade na esfera do Estado é uma particularidade relacionada aos problemas de caráter eminentemente público, desde que respeitadas as individualidades e a apoderação de sujeitos. Assim, a definição sobre políticas públicas está vinculada ao seu aspecto institucional, enquanto ação governamental, mas tendo em vista uma participação política e pluralista da sociedade civil e das minorias. Por políticas públicas é possível compreender:

[...] ação estatal deve estar focada no bem-estar público, trata-se de uma ação pública realizada com recursos que também são públicos, porque tanto os objetivos quanto os mecanismos ou procedimentos através dos quais a ação governamental se concretiza devem fazer com que se obtenha o maior bem-estar possível da forma mais eficiente. Dessa forma, a PP tem o objetivo de encarar e resolver um problema público de forma racional através de um processo de ações governamentais. (VÁZQUEZ; DELAPLACE, 2011, p. 89).

O início de uma proposta de políticas públicas segue a lógica do surgimento de um problema considerado público. Assim, a proporção de caráter "público" é essencial, porque existem problemas que, embora afetem muitas pessoas (problema social), podem não ser considerados públicos (VÁZQUEZ; DELAPLACE, 2011, p. 37). Outrossim, torna-se um desafio à implantação de políticas públicas que estejam em sinonímia 
com a perspectiva dos direitos humanos pelos governos democráticopopulares.

Tendo em vista essa necessidade de olhar para os problemas construídos como públicos, o questionamento recai acerca do instrumento para efetivação dos direitos humanos e resolução dessas demandas a partir do próprio Estado. Vázquel e Delaplace (2011, p. 37) vão afirmar que o meio para tal efetividade ocorre pelas políticas públicas, desde que elas correspondam à dignidade da pessoa humana. Assim, cabe a esse princípio-fundamento do ordenamento jurídico vincular os poderes públicos à sua efetivação, não apenas de modo programático, mas também concreto. Portanto, para além da retórica acerca da dignidade da pessoa humana, o ponto crucial diz respeito à sua aplicabilidade no plano material.

De acordo com a Ministra Carmen Lúcia Rocha (1999), "o princípio da dignidade da pessoa humana entranhou-se no constitucionalismo contemporâneo, daí partindo e fazendo-se valer em todos os ramos do Direito". Ao adotar essa perspectiva, o campo jurídico estabeleceu outra forma de pensar a realidade socioeconômica e política, baseada nos direitos humanos e aplicada às políticas públicas. A autora ainda enaltece o princípio da dignidade da pessoa humana e sua importância para a construção de políticas públicas:

Esse princípio vincula e obriga todas as ações e políticas públicas, pois o Estado é tido como meio fundado no fim que é o homem, ao qual se há de respeitar em sua dignidade fundante do sistema constituído (constitucionalizado). É esse acatamento pleno ao princípio que torna legítimas as condutas estatais, as suas ações e as suas opções (ROCHA, 1999, p.).

Por conseguinte, a perspectiva da dignidade da pessoa humana torna-se essencial para "todo o ciclo de vida de construção de uma política pública, ou seja, cada um dos processos que formam o ciclo de vida deve ser dotado da perspectiva dos direitos humanos" (VÁZQUEZ; DELAPLACE, 2011, p. 50) 
Dentro dessa abordagem analítica, há uma espécie que corresponde à política penitenciária, vinculada às políticas públicas eminentemente direcionadas à execução penal, estabelecimentos prisionais, práticas voltadas à reintegração social, apoio ao egresso etc. O órgão responsável por esse setor da Administração Pública é o Conselho Nacional de Política Criminal e Penitenciária. Apesar do liame de termos, essa forma de política pública não se confunde com política criminal $^{4}$. A primeira está relacionada aos fins valorativos de políticas e aplicação dogmática, a depender de diretrizes ao Poder Judiciário, com fins de descriminalização ou concessão de benefícios, por exemplo. A segunda diz respeito às práticas pelo Poder Executivo em termos de sistema prisional.

Como fins, o Conselho Nacional de Política Criminal e Penitenciária, enquanto órgão da execução penal, busca a implementação de políticas voltadas à questão criminal, a partir de periódicas avaliações do sistema criminal, criminológico e penitenciário, bem como a execução de planos nacionais de desenvolvimento quanto às metas e prioridades da política a ser executada. ${ }^{5}$

Assim, tem-se que a política penitenciária é uma espécie de política pública aplicada ao setor de segurança pública e execução criminal, enquanto questões consideradas de caráter público, bem como aos problemas que envolvem mulheres em situação de prisão.

4 Quanto à conceptualização de Política Criminal, mister apontar para uma possível conjectura de que raras são as vezes que há uma abordagem propriamente dita sobre Política Criminal no Brasil, em relação aos trabalhos que envolvem Dogmática-Jurídico-Penal e Criminologia (esta enquanto pensamento e discursos). Embora isto possa ocorrer, é possível encontrar algumas descrições que apontam para uma abordagem epistemológica da Política Criminal. Nesse sentido, entendese tal como:A política criminal é um sector objetivamente delimitado da política jurídica geral: é a política jurídica no âmbito da justiça criminal. Em síntese, "impõe-se especialmente à Política criminal a tarefa de rever e, em caso dado, delimitar novamente a zona penal, assim como medir a forma operativa das sanções segundo a missão da justiça criminal."(FERNANDES, 2001, p. 47).

5 Sobre o Conselho Nacional de Política Criminal e Penitenciária, vide o endereço eletrônico: <http:// portal.mj.gov.br/cnpcp/data/Pages/MJE9614C8CITEMID8137E1B511B64FE786D7957134 8AF935PTBRNN.htm>. Acesso em: 13 nov. 2014. 
No que diz respeito ao gênero, a visão dos problemas sociais no tocante às mulheres costuma ser abarcada acerca da violência doméstica, principalmente no que diz respeito à demanda pela atuação do sistema de justiça criminal em punir agressores com maior rigor. Assim, o tema da violência doméstica ganha destaque no movimento feminista e na agenda de políticas públicas. Contudo, mulheres encarceradas, que são, de forma muito simbólica, violentadas cotidianamente pelo sistema carcerário, acabam esquecidas no espaço das políticas públicas voltadas às mulheres. Transpor paradigmas sobre a figura da mulher enquanto agressora é essencial à implementação de políticas àquelas mulheres em situação de prisão, a partir de uma perspectiva de reconhecimento delas no contexto de direitos e garantias e na defesa da dignidade da pessoa humana.

Destarte, políticas penitenciárias voltadas às mulheres presas carecem estar em sinonímia à dignidade da pessoa humana, a fim de garantir direitos básicos. Além das questões gerais que envolvem o sistema prisional, como exclusão, marginalização socioeconômicacultural e estigmatização da clientela negra e pobre, há outras particularidades em matérias de direitos humanos que são colocadas em diversas situações de vulnerabilidade relacionadas às/aos filhas/os, ao período de gestação, subsistência material da família, autonomia do corpo e liberdade para exercício reprodutivo e sexual.

Ademais, "o impacto danoso do encarceramento não age apenas sobre o detento, mas também, e de modo mais insidioso e injusto, sobre sua família (WACQUANT, 2004). Portanto, a violação de direitos humanos das mulheres encarceradas representa mais uma fissura do sistema criminal, além de atingir diretamente toda a sua família e o destino de outras vidas.

Por isso, no tocante à prisão, uma saída em curto prazo para a efetivação desses direitos corresponde à construção de políticas públicas voltadas às necessidades específicas dessas mulheres. Outrossim, um dos principais elementos ao reconhecimento dos direitos humanos é a construção do sujeito de direitos. Por conseguinte, 
torna-se imprescindível que essas propostas em matéria de políticas públicas levem em consideração as vozes dessas próprias mulheres encarceradas. Nesse sentido:

O empoderamento do sujeito esteja ligado ao direito à igualdade, a não discriminação, a ações afirmativas e à perspectiva de gênero; ele identificação de grupos em situação de vulnerabilidade, os elementos estruturais que geram essa condição (opressão estrutural) e a modificação dessas estruturas (não só mediante ações afirmativas, mas também através de ações transformativas) deixando claro que os DH são interdependentes, inter-relacionados e, por isso mesmo, indivisíveis. (VÁZQUEZ; DELAPLACE, 2011, p. 41).

Embora seja necessário elaborar políticas públicas voltadas às mulheres em situação de prisão, enfrenta-se a problemática que envolve "assegurar" direitos sociais e fundamentais por meio da prisão e, simultaneamente, deixar de efetivar esses direitos com recurso às políticas sociais. Portanto, o risco dessa lógica recai na estratégia de tornar a prisão - que é um instrumento violador de direitos humanos uma via de "garantir" direitos básicos que o Estado não o faz, para além dos muros da prisão.

\section{De política social à política prisional}

Conforme exposto, os objetivos de uma política pública buscam dar racionalidade às ações governamentais (VÁZQUEZ; DELAPLACE, 2011, p. 37). A política social difere-se da política penitenciária e criminal por seus objetivos e pelas condições de vulnerabilidade dessas pessoas. Contudo, por vezes, o conflito entre os conceitos ocorre na aplicabilidade dessas políticas. É sabido que o perfil da população carcerária tem marcadores sociais de raça e classe social. Assim, a prisão emerge como uma alternativa de política social para essas pessoas que já estão em uma condição de vulnerabilidade e exclusão social. Para melhor compreendermos essa inversão ideológica, far-se-á necessário traçar 
uma breve contextualização acerca do fenômeno da globalização e neoliberalismo.

Segundo Ulrich Beck (2003, p. 184), o significado de globalização é viciado por alguns autores que ficam presos à ideia unilateral de globalização como um rompimento e extensão espacial, de localização. Entretanto, o termo globalização não significa apenas abolição de fronteiras, mas a delimitação e fortificação de outras novas fronteiras.

A cultura tirânica do narcisismo e da intimidade, com recurso à maciça individualização das massas, leva ao enfraquecimento da política e das ações na esfera pública, bem como à crise do senso de solidariedade, que passa a ser substituído pelo discurso da competitividade e eliminação do Outro (LINCK, 2010, p. 214).

A busca pela proteção contra o crime torna-se, ao mesmo tempo, obsessão e produto. Os valores legitimados pela coletividade, que surgem em decorrência do medo, começam a aparecer de forma sutil, como em "pesquisas de opinião e manchetes sensacionalistas, para rapidamente se cristalizarem nas mais variadas formas de comportamento e ação" (PESTANA, 2003, p. 66).

A influência do medo como fomento às políticas públicas, cada vez mais voltadas ao aparato punitivo do Estado, gera a criminalização em nome de uma idealizada "segurança cidadã". A naturalização e aceitação dessa política, por meio de discursos simbólicos, acabam expandindo a atuação do controle social formal.

A resposta simbólica ao problema da criminalidade concentra-se nos efeitos do delito, deixando de voltar suas propostas para as raízes estruturais (econômicas e sociais) e político-ideológicas da questão (ARGÜELLO, 2005, p. 2). Assim, a política de enfrentamento do crime é endereçada àquelas pessoas seletivamente consideradas como "criminosas" pelo controle formal, em vez de atacar a violência estrutural na qual estão inseridas (pobreza, exclusão e desigualdade social).

O Estado, portanto, deve limitar-se ao papel de coadjuvante no cenário de sua própria desconstituição: eliminar o sistema 
de proteção social, controlar os gastos públicos, reduzir impostos e taxas, flexibilizar o mercado de trabalho (permitir ao mercado o emprego de um mínimo de trabalhadores, extraindo-lhes o máximo de produtividade). (ARGÜELLO, 2005, p. 3).

A partir dessa ideologia, o Estado passa a adotar políticas criminais e penitenciárias com o pragmatismo utilitarista que se impôs na legislação penal, aproveitando as demandas simbólicas para maior intervenção do aparato penal. O Estado passa a assumir a sua incapacitação seletiva e cria respostas rápidas para anseios e medos da sociedade, por meio do "mecanismo mais simples de retórica política, a saber, a expressão de sentimentos punitivos" (FONSECA, 2012, p. 319).

Essa postura adotada por parte do Estado ficou evidente na fala de uma Defensora Pública do estado do Ceará, entrevistada pela equipe de pesquisa "Dar à Luz na Sombra": "O juiz acaba lidando com a prisão como uma política social. Qual é a política social que o Estado adota para essas pessoas vulneráveis? O presídio, né? Onde tem onde, como dormir, e tudo." Portanto, o Poder Judiciário faz da prisão uma espécie de justiça social, o que representaria um desrespeito às previsões legais e denota a postura paternalista e punitivista do Judiciário.

Outra problemática apontada em relação à prisão foi sobre a sustentabilidade da mãe ou gestante que está presa em regime domiciliar, tendo em vista a restrição estabelecida pela prisão cautelar de exercer atividades externas. A diretora da Unidade Feminina manifestou-se quanto à inexistência desses benefícios àquelas mulheres na justiça criminal de Fortaleza.

Aqui só existe mesmo o auxílio reclusão. Essa questão das mães da creche, não existe esse vínculo, porque, geralmente, ao sair, que é concedida a prisão domiciliar, ela sai e nós não sabemos como fica. Nunca foi ventilada essa situação de como iria ficar, né? Algumas, devido à renda paupérrima, têm situações que muito melhor ela estar aqui do que estar lá fora. No geral, elas são paupérrimas. (Grifo nosso) 
Assim, essa seria a escolha governamental, em matéria de políticas públicas, a redefinir os problemas sociais em termos de segurança pública, ao empregar o Estado Penitência, que denota um superinvestimento carcerário, em consequência do desinvestimento social.

\section{O caso do estado do Ceará: contextualizando o campo de pesquisa}

O campo do estado do Ceará compõe a pesquisa "Dar à luz na sombra: condições atuais e futuras de exercício da maternidade por mulheres em situação de prisão"6 (Projeto Pensando o Direito SAL(MJ)/IPEA), que contempla outros cinco estados brasileiros, além da unidade prisional feminina em Buenos Aires (Argentina). Utilizou-se da abordagem empírica, com uso das técnicas de entrevistas e visitas in loco.

O recorte do estado do Ceará ficou adstrito à cidade de Fortaleza, uma vez que estabelecimento, atrizes e atores do sistema de justiça criminal e sociedade civil estavam situados na capital cearense. Ao total, foram sete pessoas que aceitaram e contribuíram voluntariamente para a pesquisa. Foram entrevistadas a diretora e a psicóloga do Instituto Penal Feminino Desembargadora Auri Moura Costa, o diretor e a tesoureira da Creche Amadeu Barros Leal (incentivadores do projeto), uma defensora pública do estado do Ceará, assim como a Secretária de Justiça e Cidadania do Estado do Ceará.

O estado do Ceará possui apenas um presídio feminino, denominado Desembargadora Auri Moura Costa, que foi inaugurado em 1974, no antigo prédio da Congregação do Bom Pastor, no centro de Fortaleza. No ano 2000, o antigo instituto Auri Moura Costa foi

As autoras desse artigo compuseram a equipe de pesquisa, inclusive uma delas com a coordenação da pesquisa e equipe. É possível acessar o relatório final publicado: <http:// participacao.mj.gov.br/pensandoodireito/maternidade-no-carcere/>. 
transferido para uma zona afastada do centro urbano, sendo agregado a todo o complexo penal local. Atualmente, o presídio tem capacidade para 374 presas, com uma superlotação de 574 (entre provisórias e sentenciadas), atendendo a uma demanda de 184 municípios, além de presidiárias originárias de outros estados e/ou países.

Registra-se que, no Ceará, há cerca de 16.000 pessoas em situação de prisão, sendo o número total de mulheres presas equivalente a 797 (tanto na Unidade Feminina quanto em cadeias públicas), conforme o levantamento elaborado pela Coordenadoria Especial de Políticas Públicas para a Mulher e Instituto de Pesquisa e Estratégia Econômica do Ceará, realizado em junho de $2011 .{ }^{7}$ Dentre essas mulheres, apenas $4,70 \%$ encontram-se presas na unidade Auri Moura Costa. ${ }^{8}$

Acerca do estado civil das mulheres em situação de prisão, constata-se que $53,8 \%$ delas afirmam estar solteiras, $12,8 \%$ em união estável e $8 \%$ encontram-se casadas. Essas informações chamam atenção quando conhecida a existência de um cadastro realizado com o companheiro ou companheira, que é pré-requisito para que a presa possa receber a visita íntima.

Conforme informado à equipe de pesquisa, um dos questionamentos feitos no cadastro é sobre a situação e estabilidade do vínculo afetivo, de modo que se possa coibir a visita de pessoas que não têm uma relação concreta com a presa. De fato, apenas $73,7 \%$ das detentas não recebem visita íntima.

No que tange aos filhos, $78,3 \%$ das mulheres têm filhos, com a maioria tendo de um a dois filhos/as (21\% têm dois filhos; $20,6 \%$ somente um; $16 \%$ três e $11,3 \%$ quatro filhos/as). No total, $83 \%$ das

De modo geral, as informações e dados da Contextualização do presente campo foram extraídos do projeto "Mulheres em Situação de Prisão do Ceará: quem são e como estão", realizado pela Coordenadoria Especial de Políticas Públicas para a Mulher e Instituto de Pesquisa e Estratégia Econômica do Ceará, em junho de 2011. Disponível em: <http://arquivo.mulheressocialistas.org. br/bib/b9.pdf >. Acesso em: 05 fev. 2014.

8 Departamento Penitenciário Nacional. Mulheres presas: dados gerais, 2011. 
presas possuem até três filhos. Dentre as mães presidiárias e seus filhos, na ocasião de visitas ao cárcere, $22 \%$ delas não recebem visitas, provocando, possivelmente, fragilização dos vínculos afetivos.

Durante 18 meses, foi realizado o projeto "Brincar Viver-Ver", realizado pelo Instituto da Infância, em parceria com a Secretaria de Direitos Humanos da Presidência da República e com cooperação técnica da Secretaria de Justiça e Cidadania do Estado do Ceará, no Instituto Penal Feminino Desembargadora Auri Moura Costa. O objetivo do projeto consiste em fomentar o fortalecimento de vínculos familiares entre as mães presas e seus filhos até 11 anos, visando à reintegração tanto da egressa no contexto familiar quanto daquelas que estão com seus filhos no cárcere. ${ }^{9}$

Vale ressaltar que esse projeto teve como protocolo de atendimento às mães presidiárias um modelo de ficha sobre a mãe encarcerada, contendo perfil, características, dados familiares, dados socioeconômicos etc. Essas informações são colhidas com recurso à equipe multiprofissional da unidade para elaborar um "Plano de Acompanhamento Familiar", voltado especificamente à mãe encarcerada, de modo a assegurar uma articulação com a rede sócioassistencial, pelo modelo PAF (modelo para acompanhamento das famílias em situação de vulnerabilidade pelos Centros de Referência de Assistência Social).

Quanto ao acesso à justiça, mais da metade das mulheres (58,2\%) são assistidas pela Defensoria Pública do Estado. Esse atendimento é realizado semanalmente, sendo dois defensores públicos responsáveis: uma defensora pública vinculada apenas às presas provisórias e outro à execução criminal.

De acordo com o último levantamento realizado especificamente sobre mulheres em situação de prisão no presídio feminino, no ano de

9 Informações sobre o Projeto "Brincar Viver-Ver" disponíveis em: Souza e Laffite, (2013. p. 18). 
2011, identificou-se que 3,5\% das mulheres estavam grávidas e, dentre estas, apenas $2,2 \%$ realizavam o pré-natal.

\section{Criando diálogos entre redes da sociedade civil, Secretaria de Justiça e Cidadania e gestão penitenciária: as políticas públicas do estado do Ceará}

Conforme será problematizado adiante, o Ceará se destacou em relação ao fluxo estabelecido entre Secretaria de Justiça, unidade prisional, Defensoria Pública e iniciativas vindas da sociedade civil, o que ficou bastante evidente nas entrevistas que foram realizadas.

A unidade prisional feminina do estado foi, de forma geral, aquela que mais atendeu aos preceitos de dignidade humana, dentre as unidades visitadas pela equipe de pesquisa. Essa avaliação foi fruto da observação dos serviços e fluxos penitenciários, e da interlocução entre gestão prisional e Secretaria de Justiça e Cidadania do Estado do Ceará. Há políticas advindas da Secretaria que são implementadas na unidade penal. $O$ fato de a Secretária de Justiça ser originalmente uma defensora pública pode influenciar a maneira como lida com o sistema prisional. Assim, a iniciativa da Secretaria junto à gestão do estabelecimento prisional é uma forma tanto de abertura às propostas de projetos às mulheres em situação de prisão, mas também uma via de maior controle, fiscalização e análise de resultados e impactos de uma política implementada.

Uma determinação interessante é que, segundo a Secretária de Justiça e Cidadania do Estado do Ceará, em dia de visitas, as presas não ficam de uniforme, "como forma de amenizar o ambiente inerente à prisão e permitir maior semelhança a um ambiente familiar".

Nas visitas e entrevistas realizadas, ficou clara a existência de planejamento, políticas e uniformizações das decisões relacionadas ao cotidiano prisional. Por exemplo, a dinâmica das visitas é regulada por uma portaria estadual da Secretária de Justiça junto ao Conselho Penitenciário e oficiada à coordenadoria do Tribunal de Justiça do Ceará. 
Há o dia mensal de visitas apenas de crianças à Unidade, para garantir que elas sejam recebidas de forma personalizada (a visita ocorre no pátio externo, fora do ambiente prisional, e são contratados animadores e brinquedos para recebê-las).

Outra iniciativa é a presença de um curso de bacharelado em Filosofia na Unidade. O curso é oferecido pela Faculdade Católica de Fortaleza e representa o primeiro de uma série de cursos de bacharelados que se pretende implantar. Há também uma biblioteca itinerante organizada por duas detentas, que passam pelas alas para empréstimo de livros. Sobre isso, a defensora pública entrevistada entende ser necessário criar uma capacitação nas universidades e em escolas sobre a relação entre gênero e prisão, como forma de sensibilizar as pessoas sobre esses temas e espaços.

A equipe, durante a visita na penitenciária, teve a oportunidade de ouvir músicas vindas de alto-falantes e ver detentas com radinhos colados ao ouvido. As músicas eram transmitidas pela "Rádio Livre", rádio do Sistema Penitenciário do Ceará, que atinge em média 6.000 detentos, com programação das $8 \mathrm{~h}$ às $19 \mathrm{~h} .{ }^{10}$ Para além da programação musical, há dicas de direitos, recados de familiares e dedicatórias de músicas. Trata-se de iniciativa da Secretaria de Justiça em parceria com as unidades prisionais do estado do Ceará. Naquele momento, havia presos e presas trabalhando na rádio.

No plano das relações pessoais com filhas/os dessas mulheres encarceradas, de acordo com Raquel Costa de Souza Santos (SANTOS, 2011, p. 48), "a maternidade atrelada ao contexto de prisão assume significações muito particulares e representa, na maioria das vezes, a oportunidade de cuidar dos filhos e minimizar o sofrimento e o "peso" do cumprimento da pena". O exercício de maternidade e questões de gênero no cárcere são confrontados pelo poder de custódia do Estado Penal, ao qual essas mulheres estão subordinadas. Assim, a gestão

10 Disponível em: <http://www.sejus.ce.gov.br/index.php/component/content/article/54-categoriavideo/1268-radio-livre>. 
da política penitenciária é que irá estabelecer os limites temporais e os recursos materiais sobre o convívio e destino das/os filhas/os dessas mulheres.

Apesar da arbitrariedade por parte de algumas direções penitenciárias ao estabelecer o limite que cada detenta poderá ficar com sua criança no estabelecimento prisional, o estado do Ceará adota uma descentralização dessas decisões, que cabem à Secretaria de Justiça e Cidadania do Ceará.

Em matéria de políticas públicas, foi emitida uma portaria pela Secretária de Justiça e Cidadania junto ao Conselho Penitenciário e oficiada pela coordenadoria do Tribunal de Justiça do Ceará, de modo a estabelecer uma uniformidade no tocante aos dias de visitas nas prisões de todo o estado. Assim, os dias de visitas são regulamentados e estabelecidos para o seu efetivo cumprimento e fiscalização externa, tal como apontado anteriormente acerca do dia de visitas das crianças.

Acerca da rede entre sociedade civil e instituições prisionais, a Creche Amadeu Barros Leal - entidade civil e sem fins lucrativos - foi construída em terreno cedido em regime de comodato pelo Bom Pastor, há cerca de 20 anos, ao lado do presídio feminino Desembargadora Auri Moura Costa. Durante os primeiros oito anos, a unidade materno-infantil foi reservada exclusivamente a filhos/as de presos/as.

Conforme esclarecido por uma das incentivadoras do projeto de construção da creche e atual tesoureira ${ }^{11}$, o objetivo da creche era de "aproximar a mãe e filho e conservar, preservar vínculos familiares. A gente aqui tem essa preocupação: resgate da sua cidadania" (fala transcrita). A entrevistada ainda completa sobre o momento em que a creche foi criada:

Quando a creche foi criada, ela foi criada com essa ideia: de aproximar a mãe e não separar a mãe e filho. [...] Elas

11 Sobre a função exercida pela incentivadora da Creche, conferir o endereço eletrônico da Creche Amadeu Barros Leal: <http://www.crecheamadeubarrosleal.org.br/>. 
perdiam. Então elas fizeram esse apelo. Se a direção do presídio quisesse fazer um trabalho bom, precisava olhar esse lado (de separação entre mãe e filho/a). Eu peguei essa reivindicação e procurei a Secretaria de Justiça. Aí quando eu cheguei na Secretaria de Justiça, disseram para eu falar com o sub-secretário adjunto, que era o Dr. Cesar. Então pronto. Já tinha tudo pronto, legalmente ela existia.

A creche, naquele período, incumbiu-se do papel de cuidados às crianças com pais em situação de prisão e sem parentes externos que delas pudessem tutelar. No ano de 1993, inaugurava-se a Creche Amadeu Barros Leal, baseada em um modelo arquitetônico cubano, de natureza filantrópica, tendo por finalidade a prestação de assistência social e educacional a crianças carentes de 0 a 6 anos de idade, mesmo que suas mães ainda estivessem cumprindo pena, ressalvadas as exceções.

A creche foi construída ao lado da prisão feminina, porém, atualmente, ela funciona fora da prisão, sem pertencer ao sistema prisional, mantendo assim sua independência. A diretora do presídio feminino denominado Desembargadora Auri Moura Costa informou à equipe sobre a dinâmica interna entre creche e prisão, antes da construção da atual unidade feminina:

Ela saía da unidade e só ia para lá. Era tudo dentro do complexo, só que ela não ficava porque lá não tinha estrutura para que a mãe ficasse com os filhos. E aí essa criança, ela também poderia que um familiar vir, levar aquela criança para casa. Ela não estava ali presa.

Com a construção do presídio feminino fora do perímetro urbano, a creche diversificou o atendimento e passou a receber crianças carentes de toda a sociedade civil. Hoje em dia, com capacidade para 100 crianças, a creche atende a cerca de 50 filhos e filhas de pessoas presas, razão pela qual firmou um convênio com a Secretaria de Justiça, que lhe repassa uma importância mensal, assegurando, inclusive, que quatro sentenciadas cumpram pena na instituição, decorrente de um 
convênio firmado com a Prefeitura de Fortaleza e o apoio da Vara de Execução de Penas Alternativas.

Segundo o representante e fundador da creche, a entidade não tem obrigação com o presídio feminino local, uma vez que, segundo ele: "Se fossemos fazer isso, romperíamos o ciclo de atenção à própria criança. Uma criança deslocar para creche. As visitas são aos finais de semana e a creche só funciona durante a semana. Então a creche nem poderia ajudar nesse sentido, né?".

Recentemente, apesar do sufrágio da prefeitura, a maior parte dos recursos voltados à sustentabilidade da creche advém de várias outras instituições privadas e de trabalhos voluntários. Nas palavras do entrevistado: "A creche é particular, não é da prefeitura. A prefeitura apoia." Nisso resulta uma problemática sobre a continuidade da creche, uma vez que sua existência depende exclusivamente de iniciativas e vontades do próprio incentivador do projeto, sem que haja qualquer descentralização e despersonalização das decisões futuras a serem tomadas e dos recursos que serão adquiridos.

Foi informado à equipe de pesquisa que a creche não costuma acolher recém-nascidos de presas, decorrente do fato da existência da creche interna ao complexo penal. Então, seria o caso da criança que está na Amadeu Barros Leal ter mais de seis meses, uma vez que a detenta tem a oportunidade de ficar com a criança até essa idade mínima prevista na Lei de Execução Penal.

Destarte, é possível notar uma atenção em articular políticas públicas tanto em matéria de sistema carcerário quanto em políticas sociais voltadas à melhoria das crianças e recém-nascidos/as cujas mães estejam presas, mesmo quando saem da prisão. Isso decorre, principalmente, pela iniciativa em estabelecer vínculos entre setores da administração pública entre si e a sociedade civil. Tais iniciativas merecem atenção e reflexão por parte de setores e conselhos de políticas públicas e da própria sociedade civil. 


\section{Creche externa e prisão domiciliar: alternativas de desencarceramento e efetividade do exercício de maternidade por mulheres encarceradas}

Para o enfrentamento do paradoxo entre institucionalização da criança por meio do cárcere versus o exercício da maternidade, a construção de creches internas ao complexo penal não representa a melhor solução. A grande aposta seria a concessão da prisão domiciliar às gestantes e recém-mães. O obstáculo para a efetivação disso consistiria no próprio Poder Judiciário, como sendo o responsável pela apreciação da concessão da prisão domiciliar.

Em entrevista com a Defensoria Pública do Estado do Ceará, uma passagem eminentemente esclarecedora sobre a lógica punitiva do sistema penal foi exposta quando questionada sobre a concessão de medida cautelar de prisão domiciliar. A representante da instituição afirmou que raramente o Judiciário a concede. Descrevendo as palavras por ela ditas:

Isso, a seu ver, se deve ao fato deste lidar com a prisão como uma política social: se for minimamente organizada a unidade, o juiz ou juíza acha melhor a prisão que a rua, por considerar haver menos suporte do lado de fora. Vitrine é o presídio feminino.

Também nos argumentos de não concessão da liberdade provisória ou da prisão domiciliar, a defensora pública ainda explica que isso ocorre em razão de a segurança pública se sobrepor, cada vez mais, ao melhor interesse da criança. Segundo a defensora, "a existência de creche tem justificado a manutenção da prisão provisória, infelizmente. A política está errada - não é investir em creche para manter a provisória, mas investir na liberdade em detrimento da prisão provisória".

Sobre esse gargalo presente no Judiciário, a deliberação leva em consideração o seguinte pressuposto: se houver vaga na creche interna, o juiz tende a não conceder o direito, uma vez que haveria a possibilidade de a mãe ficar com criança dentro da prisão. Nesse sentido, a diretoria do presídio feminino afirmou: 
Equipe DLNS: O fato de ter um berçário no estabelecimento, isso é um fator que é argumento para o juiz não conceder a domiciliar?

Entrevistada: Agora, o juiz também tá mandando relato aqui, um documento para mim, perguntando se o estabelecimento requer espaços e as condições. Eu digo o quê? Que eu disponho só de 15 vagas (vagas referentes à creche da unidade prisional).

Conforme apontado anteriormente, a maioria das mulheres presas responde por crimes de tráfico de entorpecentes, que é considerado crime hediondo - ainda que a participação dessas mulheres seja elementar. Assim, a concessão da prisão domiciliar encontra tais barreiras: a cultura punitiva e a política de guerra às drogas presentes entre protagonistas do processo penal. Para a psicóloga que atende as presas na unidade feminina, o "juiz não tem a sensibilidade de entender que tirar as mães dos filhos, levam estes às drogas ou à morte, e isso é decorrente da não concessão da domiciliar".

Neste ínterim, o fundador da Creche Amadeu Barros Leal ainda afirma: "A gente deixa de aplicar essa domiciliar porque o Estado não fornece condições. Falta fiscalização, falta essa mulher ter renda etc. A gente não está vitimizando duas vezes essa mulher?". Assim, a modalidade de cumprimento de pena (ou no processo de conhecimento) em liberdade deixa de ser aplicada por razões de falta de fiscalização e controle por porte do próprio Estado que custodia essa mulher presa.

A fim de enfrentar tal problema acerca da não concessão da prisão domiciliar por parte dos juízes/das juízas, a Secretária de Justiça e Cidadania do Estado informou à equipe de pesquisa que o estado do Ceará conta com a Central de Apoio às Penas e Medidas Alternativas, que visa, nas palavras da entrevistada, "sensibilizar juízes a concederem penas alternativas aos presos que estão em regime fechado". 


\section{Conclusão}

O escopo do presente trabalho foi traçar um breve diagnóstico em matéria de políticas públicas relacionadas às mulheres em situação de prisão, a partir do recorte selecionado do caso do estado do Ceará, fruto da pesquisa "Dar à luz na sombra: condições atuais e futuras de exercício da maternidade por mulheres em situação de prisão".

A partir de uma abordagem analítica que envolveu definições sobre políticas públicas, tornou-se possível concluir que as políticas penitenciária, criminal e social são espécies distintas do gênero "política pública". Apesar de tal distinção, a projeção fática dessas conceptualizações são - talvez propositalmente - ideologicamente invertidas: a política penitenciária (especificamente a prisão) ganhou forma de política social, a fim de garantir direitos sociais e fundamentais que são assegurados por políticas incumbentes (política social), em respeito à primazia da dignidade da pessoa humana.

De tal modo, a expansão do "Estado Penitência", punitivo, é um sintoma do desinvestimento social. Já a política criminal está vinculada ao fim valorativo das ciências criminais, dentro da lógica da estrutura metodológica desses saberes integralizados (criminologia, política criminal e dogmática-jurídico-penal).

Por fim, coube expor sobre um caso de projeto em matéria de política pública: as redes promovidas por parte de instituições que fazem parte da Administração Pública e setores particulares da sociedade civil. Os projetos voltados às pessoas em situação de prisão são vindos da Secretaria de Justiça e Cidadania do Estado do Ceará. Com isso, temse uma perspectiva menos personalíssima por parte da gestão das unidades prisionais, bem como maior fiscalização, funcionamento e estudo de eventuais impactos desses projetos implementados.

Como resposta ao paradoxo entre institucionalização da criança e exercício de maternidade, apontou-se para uma política de desencarceramento, com recurso à prisão domiciliar para as gestantes ou recém-mães, bem como foi ressaltada a importância de estabelecer 
diálogos entre comunidade e prisão, tal como apresentado pelo estado do Ceará.

\section{Referências}

ARGÜELLO, Katie. Do Estado social ao Estado penal: invertendo o discurso da ordem. $1^{\circ}$ Congresso Paranaense de Criminologia: Londrina, 2005. Disponível em: <http://www.cirino.com.br/ artigos/Artigo\%20Katie. pdf. >. Acesso em: 08 fev. 2015.

BECK, Ulrich. Liberdade ou Capitalismo: Urlich Beck conversa com Johannes Willms. São Paulo: UNESP, 2003.

BRAGA, Ana Gabriela Mendes; ANGOTTI, Bruna. Encarceramento de mulheres e exercício da maternidade no Brasil atual: algumas reflexões e propostas. $38^{\circ}$ Encontro Anual da ANPOCS: aspectos do encarceramento na sociedade contemporânea, 27 a 30 out. 2014. Disponível em: <http://www.anpocs.org/portal/index.php?option=com_ docman\&task=doc_details\&gid=9241\&ltemid=456>. Acesso em: $08 \mathrm{fev}$. 2015.

BRASIL. Ministério da Justiça. Secretaria de Assuntos Legislativos. Dar à luz na sombra: condições atuais e possibilidades futuras para o exercício da maternidade por mulheres em situação de prisão. Ministério da Justiça, Secretaria de Assuntos Legislativos. Brasília: Ministério da Justiça, IPEA, 2015.

BRASIL. Ministério da Justiça. Departamento Penitenciário Nacional. Relatório estatístico analítico. Brasília: 2012. Disponível em: < http:// portal.mj.gov.br >. Acesso em: 12 maio 2015.

. Ministério de Justiça. Departamento Penitenciário Nacional.

Dados gerais mulheres presas. Infopen Estatística. Brasília: 2011. Disponível em: <www.mj.gov.br/depen>. Acesso em: 12 maio 2015.

FERNANDES, Fernando Andrade. O processo penal como instrumento de política criminal. Coimbra: Almedina, 2001. 
FONSECA, David S. Assumindo riscos: a importação de estratégias de punição e controle social no Brasil. In: CÂNEDO, Carlos; FONSECA, David F. (Org.). Ambivalência, contradição e volatilidade no sistema penal: leituras contemporâneas da sociologia da punição. Belo Horizonte: UFMG, 2012.

INSTITUTO DE PESQUISA E ESTRATÉGIA ECONÔMICA DO CEARÁ. Coordenadoria Especial de Políticas Públicas para a Mulher. Mulheres em situação de prisão do Ceará: quem são e como estão. Fortaleza: IPECE, 2011. Disponível em: <http://arquivo.mulheressocialistas.org. br/bib/b9.pdf >. Acesso em: 12 maio 2015.

LINCK, José Antônio Gerzson. A criminologia nos entre-lugares: inclusão violenta, exclusão e subversão contemporânea. Rio de Janeiro: Lumen Juris, 2010.

PESTANA, Débora Regina. Cultura do medo: reflexões sobre violência criminal, controle social e cidadania no Brasil. São Paulo: Método, 2003.

PETCHESKY, R.P. Direitos sexuais: um novo conceito na prática política internacional. In: BARBOSA, Regina M.; PARKER, Richard (Org.). Sexualidades pelo avesso: direitos, identidades e poder. 34. ed. Rio de Janeiro: IMS/UERJ; São Paulo, 1999. p. 15-38.

ROCHA, Carmem Lúcia Antunes. O princípio da dignidade da pessoa humana e a exclusão social. Revista Interesse Público, São Paulo, n. 4, p. 23-49, 1999.

SANTOS, Raquel. Costa de Souza. Maternidade no Cárcere: reflexões sobre o sistema penitenciário feminino. 2011. Dissertação (Mestrado em Política Social). Universidade Federal Fluminense, Niterói, 2011.

SOUZA, Francis Helen Freire. LAFFITE, Luiza Torres Gerosa (Org.). Projeto Brincar Viver-Ver. Guia Metodológico: o brincar estratégico de fortalecimento de vínculos nas unidades femininas de privação de liberdade. Ceará: Instituto da Infância, 2013.

VÁZQUEZ, Daniel; DELAPLACE, Domitille. Políticas públicas na perspectiva de direitos humanos: um campo em construção. Revista 
Internacional de Direitos Humanos, São Paulo, v. 8, n. 14, p. 35-66, jun. 2011.

WACQUANT, LOIC. L'Aberration carcerale a la Française. Tradução de Estela Abreu. Revista de Ciências Sociais, Rio de Janeiro, v. 47, n. 2, p.215-232, 2004.

Recebido em: 06/05/2015

Aprovado em: 12/05/2015 